\title{
MORPHOLOGY, EMISSION AND CRYSTAL STRUCTURE OF ZnO NANOCRYSTAL FILMS CO-DOPED WITH Ga AND In ELEMENTS
}

\author{
Brahim El Filali' ${ }^{*}$, Tetyana Torchynska², Georgiy Polupan, \\ Erick Velázquez Lozada3, José A. Andraca Adame ${ }^{4}$, Jorge L. Ramirez Garcia ${ }^{5}$
}

\author{
${ }^{1}$ Instituto Politécnico Nacional, UPIITA, México City, México \\ ${ }^{2}$ Instituto Politécnico Nacional, ESFM, México City, México \\ 3Instituto Politécnico Nacional, ESIME Zac., México City, México \\ 4Instituto Politécnico Nacional, UPIIH, Pachuca, Hidalgo, México \\ 5Instituto Politécnico Nacional, ESIME Cul., México City, México
}

\begin{abstract}
The impact of Ga and In donor co-doping on morphology, crystal structure and photoluminescence (PL) has been studied in ZnO:Ga:In nanocrystal (NC) films. The films were deposited by ultrasonic spray pyrolysis on silicon substrates heated to $400^{\circ} \mathrm{C}$. For the study of double donor doping, the group of samples was prepared, where the In content was 1 at\%, but the Ga contents were varied in the range of $0.5-2.5$ at.\%. To stimulate crystallization of the films, all samples were annealed at $400^{\circ} \mathrm{C}$ for $4 \mathrm{~h}$ in a nitrogen flow (5L/min). The obtained ZnO:Ga:1.O\%In NC films are characterized by wurtzite crystal structures for all Ga concentrations. The variation non monotonous of the morphology and PL intensity of the near band edge (NBE) emission band versus Ga contents has been detected in the ZnO:Ga:1.o\%In NC films. The ZnO crystal lattice parameters do not change up to the Ga content 1.o at\%, then decreases with Ga content of 1.5 at\% and enlarging to $\geq 2.0-2.5$ at\% Ga in the films. High-quality NC films with wurtzite-type crystalline structure, planar morphology, bright NBE emission and the small intensity of defect related PL bands have been obtained for the 1.5 at\% Ga. The reasons why the parameters vary non monotonic and the optimal concentrations for the Ga/In donor type doping the ZnO NC films have been analyzed and discussed.
\end{abstract}

Keywords: Ultrasonic spray pyrolysis, Ga and In co-doping, crystal structure, emission

\section{INTRODUCTION}

Zinc oxide is a wide band gap semiconductor, which has attracted great attention over the last two decades due to its interesting optical properties, important for optoelectronic applications in blue and UV light emitting devices, solar cells and in high temperature electronics [1-4]. The high exciton binding energy (6o $\mathrm{meV}$ ) in $\mathrm{ZnO}$ promising a bright exciton emission at room temperature $[5,6]$. High optical transmittance in the visible spectral range and significant electrical conductivity have drawn attention to $\mathrm{ZnO} \mathrm{NC}$ films as transparent conduction oxide (TCO) windows for solar cells $[7,8]$.

Significant effort has been addressed to the doping study of $\mathrm{ZnO} \mathrm{NC}$ films. Undoped $\mathrm{ZnO}$ films have n-type conductivity due to the non-stoichiometry of the films and the high concentration of shallow donor defects, such as: the interstitial $\mathrm{Zn}_{\text {I }}$ clusters [9], or hydrogen atoms in oxygen sites [10]. But the conductivity of the un-doped $\mathrm{ZnO}$ films is not high enough to be used as TCO electrodes. To improve the electrical conductivity of the $\mathrm{ZnO}$ films, different donor impurities were used. The most studied impurities are the groups III (Al, Ga or In) or VII (F) dopants [11-17]. In ZnO films doped by group III atoms, electrical resistivity varying has been reported in the range from $10^{-1}$ to $7.910^{-4} \Omega \cdot \mathrm{cm}[18-20]$.
It was revealed that the resistivity is correlated with the structural and morphological characteristics of doped $\mathrm{ZnO}$ films.

The previous study had shown that group-III elements are important donor impurities for the TCO technology based on $\mathrm{ZnO}$ films. However, it was revealed that the free electron density in the Al-doped

$\mathrm{ZnO}$ films was limited to about $10^{19}-10^{21} \mathrm{~cm}^{-3}$. This limit in the $\mathrm{ZnO}$ films was approached for the $\mathrm{Al}$ content of 1-4 at\% [21-23] and for the In content at 2 at\% [24]. The n-type doping limits in $\mathrm{ZnO}: \mathrm{Al}$ [25] or $\mathrm{ZnO}: \mathrm{Ga}$ [26] films, as assumed, are connected with the selfcompensating effect, associated with the generation of acceptor-type defects to counteract donor doping. However, the factors that stimulate the selfcompensating effect remain to be investigated.

The ionic radii of the group III elements are different and close to the ionic radius of $\mathrm{Zn}$ [27], which makes it possible to expect that the highest concentrations of In and $\mathrm{Ga}$ ions in $\mathrm{ZnO}$ NCs can be obtained without significant distortion of the $\mathrm{ZnO}$ crystal lattice. Moreover, using the co-doping by $\mathrm{Ga}$ and In atoms, which are characterized by lower (Ga) and higher (In) ionic radii compared to those of $\mathrm{Zn}$ ions, we hope to obtain the important information concerning the factors that favor to the self-compensating effect. 
The ZnO:Ga:In films, presented in this work, were grown by ultrasonic spray pyrolysis (USP) with the following annealing at $400{ }^{\circ} \mathrm{C}$ in a nitrogen flow. The USP method is widely used for $\mathrm{ZnO}$ film growth due to its inexpensive technology. Actually, ZnO:Ga:In films with bright NBE emission at $300 \mathrm{~K}$ were obtained.

\section{EXPERIMENTAL DETAILS}

Thin films of $\mathrm{ZnO}$ :Ga:In were grown by ultrasonic spray pyrolysis on 2-inch, (100) oriented silicon substrates heated to $400^{\circ} \mathrm{C}$ [28]. The methanol, water, and acetic acid solution in the 80:10:10 ration with $0.2 \mathrm{M}$ zinc acetate $\left(\mathrm{C}_{4} \mathrm{H} 6 \mathrm{O}_{4} \mathrm{Zn} \cdot \mathrm{xH}_{2} \mathrm{O}\right)$ was applied as the $\mathrm{Zn}$ precursor. In acetate hydrate $\left(\left(\mathrm{CH}_{3} \mathrm{CO} 2\right)_{3} \mathrm{In}\right.$ $\mathrm{xH} 2 \mathrm{O})$ or $\mathrm{Ga}$ acetate hydrate $\left(\left(\mathrm{CH}_{3} \mathrm{CO} 2\right)_{3} \mathrm{Ga} \times \mathrm{H}_{2} \mathrm{O}\right)$ in different contents were used as precursors of In or Ga. The content of the In atom in the solution were chosen to obtain of 1.0 at\% In in all films. But the Ga concentrations were varied in the range of $0.5-2.5$ at\% $\mathrm{Ga}$ in the $\mathrm{ZnO}$ films. The crystallization of the films was carried out at $400^{\circ} \mathrm{C}$ for $4 \mathrm{~h}$ in a constant flow of nitrogen (5L/min).

A scanning electronic microscope (SEM), model JSM780oF-JEOL was used to monitor the film morphology [29]. A diffractometer, Model XPERT MRD with Pixel detector, three-axis goniometry, parallel collimator, and X-ray beam of the $\mathrm{Cu}$ source (line Ka1 $1.5406 \AA$ ) was used to study the XRD patterns. PL spectra were detected on a SPEX 500 spectrometer with a Hamamatsu photomultiplier [30]. The light excitation source was a He-Cd laser (model KIMMON: IK3102RG) with a power of $50 \mathrm{~mW}$ and an excitation light wavelength of $325 \mathrm{~nm}$.

\section{EXPERIMENTAL RESULTS AND DISCUSSION}

The SEM images of $\mathrm{ZnO}: \mathrm{Ga}: \mathrm{In}$ films are shown in figure 1 for the In content 1.0at\% and Ga contents of 0.5, 1.5, and 2.5 at\%.

At a small $\mathrm{Ga}$ content ( $\leq 1.0$ at\%) and a high $\mathrm{Ga}$ content $(\geq 2.0$ at $\%)$, the grains are in the form of nanosheets with a size of 100-200 nm distributed randomly on the surface of the $\mathrm{ZnO}$ films (Fig.1a, c). The grain shape changes in the $\mathrm{ZnO}$ :Ga:In film with 1.5 at\% $\mathrm{Ga}$. The nanosheet shape changes to nanorod with the size of hexagonal cross sections 50-100 nm typical for the wurtzite $\mathrm{ZnO}$ crystal structure (Fig.1b). Simultaneously, the nanorod density increases and the surface roughness decreases (Fig.1b). The surface of the $\mathrm{ZnO}: 1.5 \% \mathrm{Ga}: 1.0 \%$ In film is characterized by a flat morphology suitable for device applications. Thus we have seen that the surface morphology of $\mathrm{ZnO}: \mathrm{Ga}: \mathrm{In}$ films varies non-monotonic and nanograins with the typical hexagonal cross section of wurtzite $\mathrm{ZnO}$ crystals can be obtained for the $\mathrm{ZnO}: 1.5 \% \mathrm{Ga}$ :In films.

In Figure 2, the XRD patterns of the $\mathrm{ZnO}$ thin films doped with In, and co-doped with In and Ga are shown.

The XRD pattern of the In-doped $\mathrm{ZnO}$ film includes the peaks $2 \Theta=34.37^{\circ}, 47.33^{\circ}$ and $62.73^{\circ}$ related to diffraction on the (002), (102) and (103) crystal planes in the wurtzite $\mathrm{ZnO}$ crystal structure (JCPDS file no. 003-0888) with the preferential (002) plane orientation in the film (Fig.2). Note that the XRD peak positions in $\mathrm{ZnO}: 1.0 \%$ In films are smaller, than the corresponding positions $2 \Theta=34.44^{\circ}, 47.56^{\circ}$ and $62.83^{\circ}$ detected in un-doped $\mathrm{ZnO}$ films (JCPDS file no. oo3o888), owing to the increase of the $\mathrm{ZnO}$ crystal lattice parameters at In doping. The latter is related to the higher ionic radius of the $\mathrm{In}^{3+}$ ions (o.80 $\AA$ ) compared to those for the $\mathrm{Zn}^{2+}(0.74 \AA)$ ions [31].

$\mathrm{ZnO}$ films co-doped with $\mathrm{Ga}$ and In atoms are also characterized by the wurtzite $\mathrm{ZnO}$ crystal structure (Fig.2). The XRD patterns of these $\mathrm{ZnO}$ films include the five XRD peaks $2 \Theta=31.63^{\circ}, 34.38^{\circ}, 36.14^{\circ}, 47.37^{\circ}$ and $56.54^{\circ}$ related to diffraction on the (100), (002), (101), (102) and (110) crystal planes (JCPDS file no. 003o888).

\section{a) $\mathrm{ZnO}: 0.5 \% \mathrm{Ga}: 1.0 \% \mathrm{In}$}

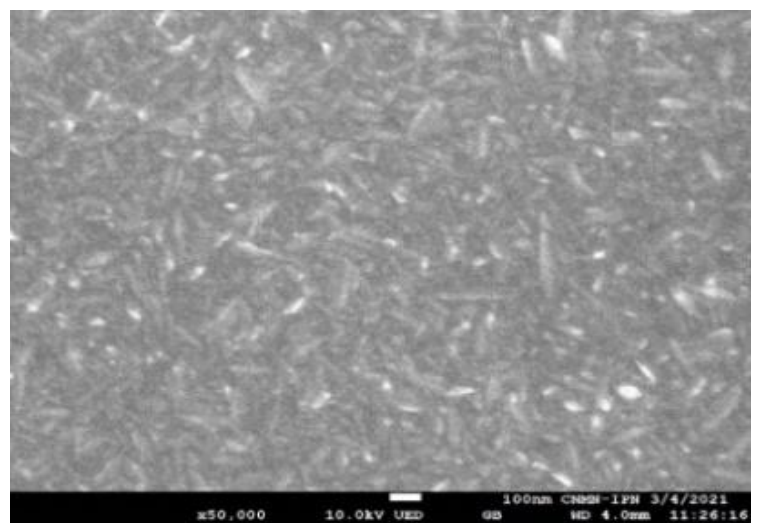

b) $\mathrm{ZnO}: 1.5 \% \mathrm{Ga}: 1.0 \% \mathrm{In}$

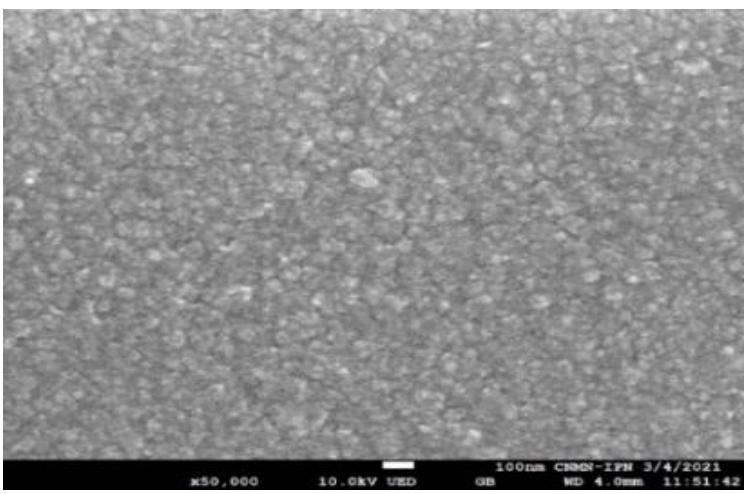

c) $\mathrm{ZnO}: 2.5 \% \mathrm{Ga}: 1.0 \% \mathrm{In}$

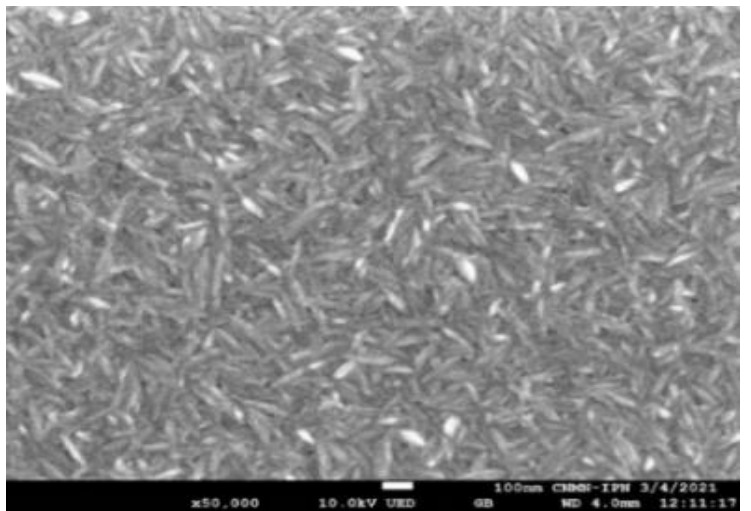

Figure 1. SEM images of studied $\mathrm{ZnO}$ films doped with 1.0at\%In and different contents of Ga atoms: 0.5at\% (a), 1.5 at\% (b), and 2.5 at\%(c) 


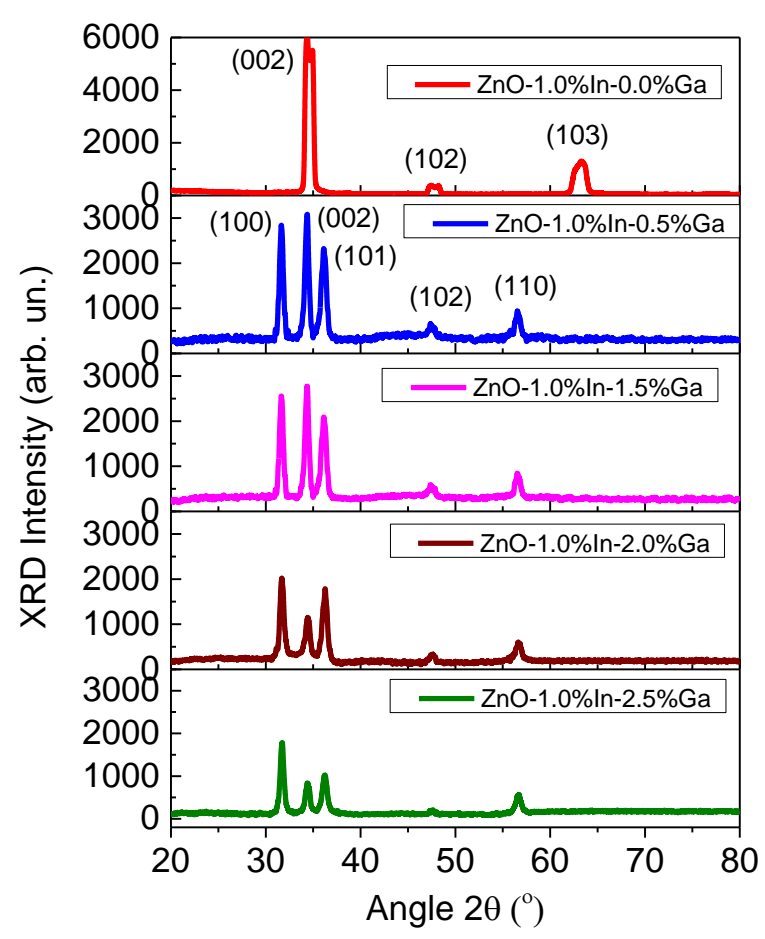

Figure 2. XRD patterns of the $\mathrm{ZnO}: \mathrm{Ga}$ :In films with different $\mathrm{Ga}$ contents mentioned on the figures

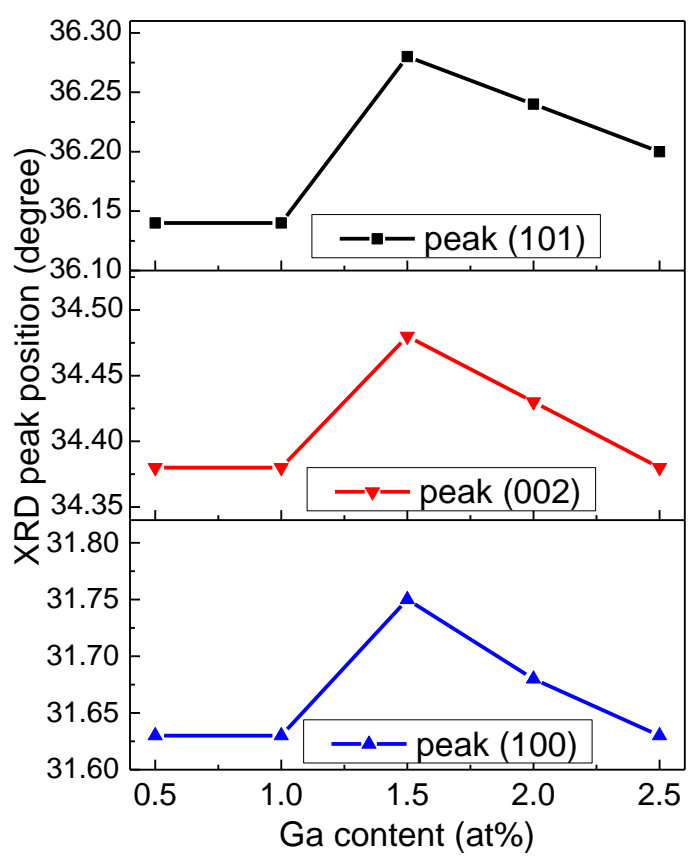

Figure 3. The shift of XRD peak positions versus Ga contents

With the increase in $\mathrm{Ga}$ concentrations in the range $0.5-1.5$ at\%, the intensities of the (100), (002), (101), (102) and (110) peaks decrease insignificantly (Fig.2), and the XRD peak positions do not change up to 1.0 at\% (Fig.3). However, with the higher Ga content of 1.5 at\% the XRD peaks shift to higher angles (Fig.3). However, at the $\mathrm{Ga}$ contents ( $\geq 2.0-2.5$ at $\%)$, the intensities of the mentioned XRD peaks move downward (Fig.2). Simultaneously, the positions of the XRD peaks are shifted towards the lower $2 \Theta$ angles (Fig.3). The last effect is related to the increase in the $\mathrm{ZnO}$ crystal lattice parameters at higher $\mathrm{Ga}$ contents due to the formation some native defects. The different reasons can stimulate the decrease of the crystallinity of $\mathrm{ZnO}$ :In films with higher $\mathrm{Ga}$ doping, such as: the increase of the $\mathrm{ZnO}$ grain density accompanied by some disorder of the $\mathrm{ZnO} \mathrm{NCs}$ and loss of the preferential (002) $\mathrm{ZnO}$ plane orientation, or the formation of complex defects related to the $\mathrm{Ga}$ ions in the $\mathrm{ZnO}$ crystal lattice.

The PL spectra of ZnO:In NC films, obtained by ultrasonic spray pyrolysis with different In contents, were investigated early by us [32]. It was shown that at small In contents (0.5-1.0 at\%) the PL bands: orange (O) centered at $2.2 \mathrm{eV}$ and green $(\mathrm{G})$ peaked at $2.5 \mathrm{eV}$, related to the native host defects, decreased and then they disappeared completely at 2.5 at\% In [32]. Simultaneously, the PL intensity of the near band edge (NBE) emission increased significantly in PL spectra of the films with 0.50-1.0 at\% In and its maximum shifted to $3.14-3.15 \mathrm{eV}$ (Fig.4a). The last fact is connected with the increase of the parameters of the $\mathrm{ZnO}$ crystal lattice at In doping, which is accompanied by the decrease of the $\mathrm{ZnO}: \mathrm{In}$ energy band gap compared to its value in undoped $\mathrm{ZnO}$ NCs $[32,33]$.

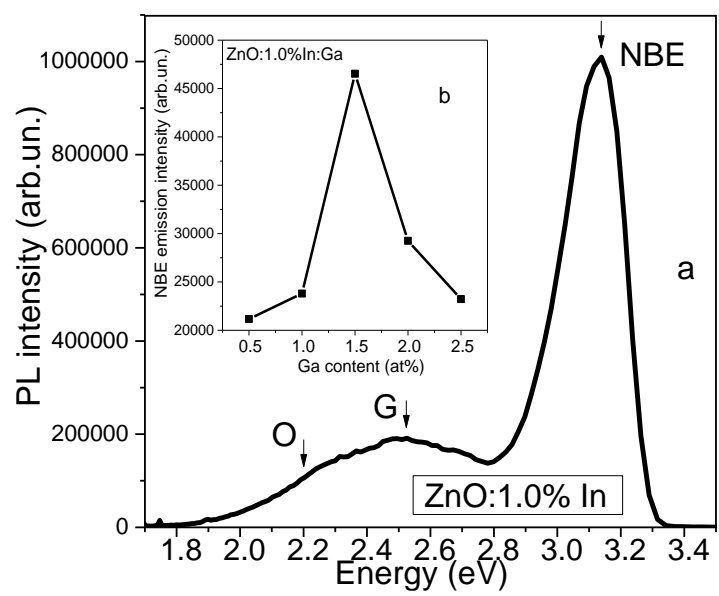

Figure 4. The PL spectrum of ZnO:I,o\%In film (a) and the dependence of the NBE emission intensity (b) in the ZnO1.0\%In:Ga films versus Ga contents

It was shown [32], that NBE emission band (centered at 3.14-3.15 eV) was related to the LO phonon replicas of the free exciton emission. It should be noted that the high intensity of NBE emission testifies to a high quality of the studied $\mathrm{ZnO}: 1.0 \%$ In films. This is one of the reasons why the In content of 1.0 at\% was used in the $\mathrm{ZnO}$ films in the work presented.

The variation of the Ga contents in the $\mathrm{ZnO}: 1.0 \% \mathrm{In}$ films stimulate the non-monotonic changes of the PL intensity of NBE emission bands (Fig.4b). The NBE emission intensity increases for the Ga content range of 0.5-1.5 at\% in ZnO:1.0\%In films (Fig.4b). But for the higher $\mathrm{Ga}$ concentrations from the range 1.5-2.5 at\% Ga, the PL intensity of the NBE emission bands decreases significantly (Fig.4b).

The non-monotonic changes in film morphology correlates with the non-monotonic change in PL intensity of the NBE emission band. It was mentioned earlier that the $\mathrm{Ga}^{3+}$ ionic radius ( $0.62 \AA$ ) is smaller and $\mathrm{In}^{3+}$ ionic radius $(0.80 \AA)$ is greater than that of $\mathrm{Zn}^{2+}$ (0.74 $\AA$ ). In the $\mathrm{ZnO}$ :In films with a small Ga contents (0.5-1.0 at\%), the compression stresses, which appear due to the In doping (1.0 at\%), prevent the effective 
oxidation and the formation of hexagonal $\mathrm{ZnO}$ nanorods at the $\mathrm{ZnO}$ film crystallization (Fig.1a). The doping with 1.5 at\% Ga makes it possible to partially compensate of compressive stresses in the films. This effect is favored by the effective $\mathrm{ZnO}$ oxidation, as well as by the dissolution of $\mathrm{Ga}$ and In ions in the $\mathrm{ZnO}$ films in thermal annealing. Simultaneously, the typical hexagonal $\mathrm{ZnO}$ nanorods growth at the crystallization (Fig.1b) and high quality $\mathrm{ZnO} \mathrm{NC}$ films have been produced with the bright NBE emission band (Fig.4).

The further increase in Ga contents to 2.0-2.5at\% leads to significant distortion of the $\mathrm{ZnO}$ crystal lattice which again prevents efficient crystallization of the $\mathrm{ZnO}$ films (Fig.1c). Simultaneously, the intensity of XRD peaks falls (Fig.2) and the XRD peak positions move towards the lower $2 \Theta$ values (Fig.3). The last effect attests to the significant dissolution of $\mathrm{Ga}$ ions in the $\mathrm{ZnO}$ crystal lattice, which is accompanied by the generation of native host defects and the decrease in the PL intensity of the NBE emission band (Fig.4b). The obtained results, as expected, will be useful for further improvement of the doping process in the $\mathrm{ZnO}: \mathrm{Ga}: \mathrm{In}$ films.

Acknowledgements: The authors thank the financial support of CONACYT Mexico (pt. 258224) and SIP-IPN, Mexico (pt. 20210400 and pt. 20210947), as well as thank Dr. Hector Calderon for permission to work on XRD equipment in his laboratory.

\section{REFERENCES}

1. A. Janotti, C. G. Van de Walle, "Fundamentals of zinc oxide as a semiconductor," Rep. Prog. Phys., vol. 72, no. 12, 126501, Oct. 2009.

DOI: $10.1088 / 0034-4885 / 72 / 12 / 126501$

2. L. Schmidt-Mende, J. L. MacManus-Driscoll, "ZnO nanostructures, defects, and devices," Mater. Today, vol. 10, no. 5, pp. 40 - 48, May 2007. DOI: $10.1016 / \mathrm{S} 1369-7021(07) 70078-0$

3. S. J. Pearton, D. P. Norton, K. Ip, Y. W. Heo, T. Steiner, "Recent progress in processing and properties of $\mathrm{ZnO}$," Prog. Mater. Sci., vol. 50, no. 3, pp. 293 - 340, May 2005. DOI: 10.1016/j.pmatsci.2004.04.001

4. N. H. Alvi, S. M. Usman Ali, S. Hussain, O. Nur, M. Willander, "Fabrication and comparative optical characterization of $\mathrm{n}-\mathrm{ZnO}$ nanostructures (nanowalls, nanorods, nanoflowers and nanotubes)/p-GaN Light emitting diodes," Scr. Mater., vol. 64, no. 8, pp. 697 - 700, Apr. 2011.

DOI: 10.1016/j.scriptamat.2010.11.046

5. T. V. Torchynska, B. El Filali, "Size dependent emission stimulation in ZnO nanosheets," J. Lumin., vol. 149, pp. 54 - 60, May 2014.

DOI: $10.1016 /$ j.jlumin.2014.01.008

6. N. Zebbar, et al., "UV and visible photoluminescence emission intensity of undoped and In-doped $\mathrm{ZnO}$ thin film and photoresponsivity of ZnO:In/Si hetero-junction," Thin Solid Films, vol. 605, pp. 89 - 94, Apr. 2016.

DOI: 10.1016/j.tsf.2015.09.061

7. J. Wienke, B. van der Zanden, M. Tijssen, M. Zeman, "Performance of spray-deposited ZnO:In layers as front electrodes in thin-film silicon solar cells," vol. 92. no. 8, pp. 884 - 890, Aug. 2008

8. DOI: 10.1016/j.solmat.2008.01.023

9. M. A. Lucio-Lopez, M. A. Luna-Arias, A. Maldonado, M. de la L. Olvera, D. R. Acosta, "Preparation of conducting and transparent indium-doped $\mathrm{ZnO}$ thin films by chemical spray," Sol. Energy Mater. Sol. Cells, vol. 90, no. 6, pp. 733 - 741, Apr. 2006.

DOI: $10.1016 /$ j.solmat.2005.04.010
10. D. C. Look, et al., "Evidence for Native-Defect Donors in n-Type ZnO,” Phys. Rev. Lett., vol. 95, no. 22, 225502, Nov. 2005.

DOI: 10.1103/PhysRevLett.95.225502

11. G. A. Shi, M. Saboktakin, M. Stavola, “"Hidden hydrogen” in as-grown ZnO," Appl. Phys. Lett., vol. 85, no. 23, 5601, Dec. 2004. DOI: $10.1063 / 1.1832736$

12. K. Ellmer, A. Klein, B. Rech, Transparent Conductive Zinc Oxide, 1st ed., New York (NY), USA: Springer, 2008. Retrieved from: 3540736123 lp.pdf (ciando.com) Retrieved on: Jan. 13, 2021

13. M. H. Mamat, et al., "Influence of doping concentrations on the aluminum doped zinc oxide thin films properties for ultraviolet photoconductive sensor applications," Opt. Mater., vol. 32, no. 6, pp. 696 - 699, Apr. 2010.

DOI: 10.1016/j.optmat.2009.12.005

14. E. Arca, K. Fleischer, I. Shvets, "Tuning the crystallographic, morphological, optical and electrical properties of $\mathrm{ZnO}$ :Al grown by spray pyrolysis," Thin Solid Films, vol. 555, pp. 9-12, Mar. 2014. DOI: $10.1016 /$ j.tsf.2013.08.110

15. F. Chaabouni, B. Khalfallah, M. Abaab, "Doping Ga effect on $\mathrm{ZnO}$ radio frequency sputtered films from a powder target," Thin Solid Films, vol. 617, no. B, pp. 95 - 102, Oct. 2016. DOI: 10.1016/j.tsf.2015.12.047

16. M. Yilmaz, "Investigation of characteristics of $\mathrm{ZnO}: \mathrm{Ga}$ nanocrystalline thin films with varying dopant content," Mater. Sci. Semicond. Process., vol. 40, pp. 99 - 106, Dec. 2015

DOI: 10.1016/j.mssp.2015.06.031

17. C. Yu et al., "Effect of Indium doping on the photoelectric properties of $\mathrm{n}-\mathrm{ZnO}$ nanorods/p-GaN heterojunction light-emitting diodes," Superlattices Microstruct., vol. 120, pp. 298 - 304, Aug. 2018. DOI: $10.1016 / \mathrm{j}$. spmi.2018.05.060

18. R. K. Gupta, K. Ghosh, R. Patel, S. R. Mishra, P. K. Kahol, "Band gap engineering of $\mathrm{ZnO}$ thin films by $\mathrm{In}_{2} \mathrm{O}_{3}$ incorporation," J. Cryst. Growth, vol. 310, no. 12, pp. 3019 - 3023, Jun. 2008. DOI: 10.1016/j.jcrysgro.2008.03.004

19. S. Edinger et al., "Highly transparent and conductive indium-doped zinc oxide films deposited at low substrate temperature by spray pyrolysis from water-based solutions," J. Mater. Sci., vol. 52, pp. 8591 - 8602, Jul. 2017.

DOI: $10.1007 / \mathrm{s} 10853-017-1084-8$

20. S. D. Ponja, S. Sathasivam, I. P. Parkin, C. J. Carmalt, "Highly conductive and transparent gallium doped zinc oxide thin films via chemical vapor deposition," Sci. Rep., vol. 10, 638, Jan. 2020.

DOI: $10.1038 / \mathrm{s} 41598-020-57532-7$

21. T. P. Rao et al., "Physical properties of $\mathrm{ZnO}$ thin films deposited at various substrate temperatures using spray pyrolysis," Physica B Condens. Matter., vol. 405, no. 9, pp. 2226 - 2231, May 2010. DOI: 10.1016/j.physb.2010.02.016

22. H. Agura, A. Suzuki, T. Matsushita, T. Aoki, M. Okuda, "Low Resistivity Transparent Conducting Al-Doped $\mathrm{ZnO}$ Films Prepared by Pulsed Laser Deposition," Thin Solid Films, vol. 445, no. 2, pp. 263 - 267, Dec. 2003. DOI: 10.1016/So040-6090(03)01158-1

23. J. G. Lu et al., "Structural, optical, and electrical properties of ( $\mathrm{Zn}, \mathrm{Al}) \mathrm{O}$ films over a wide range of compositions," J. Appl. Phys., vol. 100, no. 7, 073714, Oct. 2006. DOI: $10.1063 / 1.2357638$

24. K. Mahmooda, A. Khalid, S. W. Ahmad, M. T. Mehran, "Indium-doped $\mathrm{ZnO}$ mesoporous nanofibers as efficient electron transporting materials for perovskite solar cells," Surf. Coat. Technol., vol. 352, pp. 231 - 237, Oct. 2018. DOI: 10.1016/j.surfcoat.2018.08.039

25. J.-Y. Noh, H. Kim, Y.-S. Kim, C. H. Park, "Electron doping limit in $\mathrm{Al}$-doped $\mathrm{ZnO}$ by donor-acceptor interactions," J. Appl. Phys., vol. 113, no. 15, 153703, Apr. 2013. DOI: $10.1063 / 1.4801533$ 
26. D. C. Look et al., "Self-compensation in semiconductors: the Zn-vacancy in Ga-doped ZnO," Phys. Rev. B, vol. 84, no. 11, 115202, Sep. 2011

DOI: 10.1103/PhysRevB.84.115202

27. R. D. Shannon, "Revised effective ionic radii and systematic studies of interatomic distances in halides and chalcogenides," Acta Crystallogr. A, vol. 32, no. 5, pp. 751 - 767, Sep. 1976.

DOI: $10.1107 /$ So567739476001551

28. E. V. Lozada, T. V. Torchynska, J. L. Casas Espinola, B. P. Millan, "Emission of $\mathrm{ZnO}: \mathrm{Ag}$ nanorods obtained by ultrasonic spray pyrolysis," Physica B Condens. Matter., vol. 453, pp. 111 - 115, Nov. 2014.

DOI: $10.1016 /$ j.physb.2014.04.083

29. M. Dybiec et al., "Photoluminescence scanning on InAs/InGaAs quantum dot structures," Appl. Surf. Sci., vol. 252, no. 15, pp. 5542 - 5545, May 2006.

DOI: $10.1016 /$ j.apsusc.2005.12.125

30. T. V. Torchynska, A. Stintz, "Some aspects of emission variation in InAs quantum dots coupled with symmetric quantum wells," J. Appl. Phys., vol. 108, no. 2, 024316, Jul. 2010.

DOI: $10.1063 / 1.3455851$

31. Metallic, Covalent and Ionic Radii( $(r)$, Wired Chemist. Retrieved from:

http://www.wiredchemist.com/chemistry/data/metallic$\underline{\text { radii }}$

Retrieved on: Oct. 20, 2020

32. B. El Filali, J.A. Jaramillo Gomez, T. V. Torchynska, J. L. Casas Espinola, L. Shcherbyna, "Band-edge emission, defects, morphology and structure of in-doped $\mathrm{ZnO}$ nanocrystal films," Opt. Mater., vol. 89, pp. 322 - 328, Mar. 2019.

DOI: 10.1016/j.optmat.2019.01.056

33. T. V. Torchynska, B. El Filali, G. Polupan, "In-related complex defects and emission of in-doped $\mathrm{ZnO}$ nanocrystal films," Physica E Low Dimens. Syst. Nanostruct., vol. 113, pp. 137 - 142, Sep. 2019.

DOI: 10.1016/j.physe.2019.05.014 